\title{
Evaluation of the clinical utility of maternal alloantibody screening as a surrogate to antiglobulin crossmatch procedures in resource limited settings
}

\author{
Zaccheaus Awortu Jeremiah, Augustina Mordi
}

\begin{abstract}
Aims: In resource limited settings, cross matching procedures are usually limited to the conventional antiglobulin technique. Pretransfusion screening for red cell alloantibodies are not carried out routinely. The study was aimed at evaluating the usefulness of antibody screening as a surrogate to antiglobulin crossmatch procedure. Methods: A total 250 pregnant women attending the antenatal clinic of the Braithwaite Memorial Specialist Hospital (BMSH), Port Harcourt were screened for the presence of red cell alloantibodies using DiaMed screening and panel cells (DiaCell and DiaPanels). Results: Alloantibodies detected were anti-E (1.2\%), anti-K (o.8\%), anti-C (o.4\%) and anti-Jsb (0.4\%). The overall prevalence rate of red cell allo-antibodies was $4.8 \%$. A blind crossmatch performed using the serum of the patients on donor's cells revealed the following results, incompatible 5 (2.0\%) and 254 (98.0\%) compatible. Taking incompatible results as positive and compatible as negative, the performance indices of the antibody screening procedure was obtained as follows: sensitivity
\end{abstract}

Zaccheaus Awortu Jeremiah ${ }^{1}$, Augustina Mordi ${ }^{2}$

Affiliations: ${ }^{1}$ Haematology and Blood Transfusion Unit, Department of Medical Laboratory Sciences, College of Health Sciences, Niger Delta University, Wilberforce Island, Bayelsa State; ${ }^{2}$ Medical Laboratory Services Department, Braithwait Memorial Specialist Hospital, Port Harcourt, Nigeria.

Corresponding Author: Zaccheaus Awortu Jeremiah Ph.D P.O. Box 1437 Diobu, Port Harcourt 500001, Rivers State, Nigeria; Ph: +234 803 404;

Email: zacjerry@yahoo.com

Received: 11 February 2011

Accepted: 11 April 2011

Published: 30 September 2011
(41.6\%), specificity (100\%), PPV (100\%), NPV (97.1\%), efficiency (48.6\%). Prevalence (4.8\%) and percentage safety (41 .6\%). The study did not show the type and screen to reach the expected safety level of $\mathbf{9 9 . 0 \%}$. Its usefulness was however shown through the detection of unexpected antibodies in $4.8 \%$ of the subjects. Conclusions: We concluded that with a high specificity obtained, the detection and identification of these antibodies would help select blood in advance for patients undergoing surgery in order to reduce the incidence of haemolytic transfusion reactions.

Keywords: Antibody screening, Antiglobulin crossmatch, Pretransfusion testing, Antibody identification

$$
* * * * * * * * *
$$

Jeremiah ZA, Mordi A. Evaluation of the clinical utility of maternal alloantibody screening as a surrogate to antiglobulin crossmatch procedures in resource limited settings. International Journal of Blood Transfusion and Immunohematology 2011;1:1-6.

Article ID: 100001IJBTIZAJ2011.

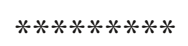

doi:10.5348/ijbti-2011-1-OA-1

\section{INTRODUCTION}

Antibody detection and identification are fundamental to the practice of immunohaematology. Antibody identification can be a guide to the clinical significance of the antibody and provides information that aids in the selection of suitable blood for transfusion. Prenatal immunohaematologic care of 
pregnant women requires the investigation of unexpected RBC antibodies in their sera during pregnancy. When RBC antibody screening is positive, it is necessary to determine specificity of the antibody, its clinical importance and the ability to cross the placenta and cause haemolytic disease of the foetus and newborn (HDFN). In some circumstances, it can be a difficult and time consuming process and thus cause a delay in patient care [1].

In Port Harcourt, as in other developing parts of the world, type and screen procedure is not routinely carried out as part of the pre-transfusion test protocol, hence the incidence of maternal red cell allo-antibodies and the prevalence of these unexpected antibodies in this locality are not known. With the high incidence rate of neonatal jaundice in Port Harcourt [2] and paucity of information on this subject, it becomes necessary for a study like this to be conducted; hence this is the first attempt ever to provide the prevalence of unexpected antibodies in this part of the world.

This study therefore aimed to; 1) provide the frequencies of allo-antibodies among pregnant women attending the Braithwaite Memorial Specialist Hospital, 2) evaluate the clinical utility of the antibody screening procedure as a surrogate to antiglobulin cross matching procedures and, 3) determine the specificity of the antibodies identified in the sera of the pregnant women.

\section{MATERIALS AND METHODS}

Study area and population: This study was conducted in Braithwaite Memorial Specialist Hospital (BMSH), Port Harcourt, and the capital city of Rivers State of Nigeria. The study population consisted of 250 pregnant women aged 16 - 45 years recruited form antenatal care clinic within the period of six months.

Study Design: A prospective cross-sectional design was used in this study. Samples were collected randomly, after obtaining a written or oral informed consent from the patients. Women from different ethnic groups were randomly recruited parameters together with sampling various blood.

Collection and processing of samples: Four milliliter of whole blood was drawn with syringe $(5 \mathrm{ml})$ through venepuncture using the antecubital vein. The whole blood was allowed to clot in the plain bottle, centrifuged at $300 \mathrm{~g}$ for five minutes and the serum separated into a separate plain tube with a cap. The separated serum was stored at $-80^{\circ} \mathrm{C}$. Serological parameters were assessed using the achived sample. All blood samples were collected at the Antenatal unit of the Braithwaite Memorial Specialist Hospital, Port Harcourt.

Determination of $\mathrm{ABO}$ and Rhesus blood groups: ABO blood grouping was done using anti-A, anti-B, and anti-AB bought from Biotec (Ipswich, UK) with standard tube agglutination technique. All blood group tests were confirmed with known test RBCs. Negative controls were included in all tests. ABO blood group tests were performed only at room temperature. Reverse grouping cells were also supplied by Biotec.

Rhesus grouping was done using anti-D monoclonal reagent bought from Biotec. Rhesus controls were supplied in all tests. Tests were done in tubes and all negative results were confirmed using indirect agglutination test technique with $20 \%$ bovine albumin and anti-human globulin (AHG) tests at $37^{\circ} \mathrm{C}$. After spinning for $20 \mathrm{sec}$ at $100 \mathrm{rpm}$, the $\mathrm{RBC}$ was gently resuspended and immediately observed macroscopically and confirmed microscopically before recording the result as positive or negative.

Antibody screening and Identification: Antibody screening panel (3 cells) and identification panel (11 cells) from DiaMed (Switzerland) was used to screen and identify alloantibodies by tube method in low ionic strength solution, albumin and AHG phase according to the manufacturer's instructions.

Antiglobulin crossmatch: Antiglobulin crossmatch using Indirect Antiglobulin Test procedure was carried out on the patients' serum with pooled donors' red cells as described by Morgan [3] by a different Medical Laboratory Scientists who was ignorant of the antibody screening results.

Compatibility testing: A negative reaction indicates compatibility of the donor blood with the recipient.

A positive reaction indicates incompatibility of the donor blood with the recipient, due to the presence of antibodies directed against antigens on the donor red cells. Further investigation to identify the antibody specificity should be performed.

Statistics: Results were analyzed using the SPSS version 16 for windows (Chicago, IL) Frequency table was used to determine the prevalence of allo-antibodies among the pregnant women. Performance indices such as sensitivity, specificity, positive predictive value, negative predictive value, efficiency, prevalence and safety level were calculated using standard formulae.

\section{RESULTS}

A total of two hundred and fifty (250) pregnant women attending the Braithwaite Memorial Specialist Hospital (BMSH) were screened for the presence of irregular antibodies.

The demographic characteristics of the pregnant women are shown in table 1. Majority of the study population were in the $26-30$ years age group (43.9\%) and in their second semester (60.4\%). Those of the Ibo ethnic group dominated the study population (28.0\%) followed by those of Ikwerre (23.8\%) and Ijaw (18.4\%). Distribution of $\mathrm{ABO}$ and $\mathrm{Rh}$ blood groups among the 250 pregnant women revealed that prevalence of group $\mathrm{O}$ was $48.0 \%, \mathrm{~A}-41.2 \%, \mathrm{~B}-7.6 \%$, and $\mathrm{AB}$ was $3.2 \%$. Rhesus D (Rh D) positive accounted for $91.4 \%$, whereas Rh D negative was $8.6 \%$ (table 2). Table 3 shows the specificity of the antibody detected in the study population. The most frequently occurring irregular 
Table 1: Demographic characteristics of the pregnant women.

\begin{tabular}{|c|c|c|}
\hline Characteristics & Number & Percentage (\%) \\
\hline \multicolumn{3}{|l|}{ Age group (vrs.) } \\
\hline $16-20$ & 4 & 16 \\
\hline $21-25$ & 30 & 12.0 \\
\hline $26-30$ & 112 & 43.9 \\
\hline $31-35$ & 70 & 27.5 \\
\hline $36-40$ & 25 & 9.8 \\
\hline $41-45$ & 9 & 3.5 \\
\hline Total & 250 & 100.00 \\
\hline \multicolumn{3}{|l|}{$\underline{\text { Trimesters }}$} \\
\hline First & 23 & 9.0 \\
\hline Second & 151 & 60.4 \\
\hline Third & 76 & 29.8 \\
\hline \multicolumn{3}{|l|}{$\underline{\text { Parity }}$} \\
\hline 1 & 71 & 27.8 \\
\hline 2 & 76 & 29.8 \\
\hline 3 & 33 & 12.9 \\
\hline 4 & 17 & 6.7 \\
\hline$>4$ & 3 & 1.2 \\
\hline o & 50 & 20.0 \\
\hline \multicolumn{3}{|l|}{ Ethnic group } \\
\hline Ijaw & 47 & 18.4 \\
\hline Ogoni & 19 & $7 \cdot 5$ \\
\hline Ekpeye & 12 & $4 \cdot 7$ \\
\hline Ikwerre & 58 & 23.8 \\
\hline Ibo & 70 & 28.0 \\
\hline Yoruba & 10 & $3 \cdot 9$ \\
\hline
\end{tabular}

antibody detected was anti-E in 3 (1.2\%) patients followed by anti-K in 2 (o.8\%) patients, then anti-C and anti-Jsb (0.4\% respectively). Three of the samples had mixed field reactions while two could not be identified using the panel cell. A total of 238 (95.2\%) samples gave negative antibody screen.

The antiglobulin crossmatch was performed on all samples and five $(2.0 \%)$ were found to be incompatible. A total of 245 (98.0\%) were compatible as shown in table 4 . Table 5 shows the clinical utility of antibody screening as a surrogate to antiglobulin crossmatch. Using performance indices and taking incompatible results as positive, the sensitivity of antibody screening method was found to be $41.6 \%$ while specificity was $100 \%$. The positive predictive value (PPV) was $100 \%$ while negative predictive value (NPV) was 97.1\%. Efficiency was $48.6 \%$ while the percentage safety of the
Table 2: Distribution of $\mathrm{ABO}$ and Rhesus blood groups among the 250 pregnant women.

\begin{tabular}{lccccc}
\hline & O & A & B & AB & Total \\
\hline Rh + & 109 & 94 & 18 & 8 & 229 \\
Rh+\% & 43.6 & 37.4 & 7.2 & 3.2 & 91.4 \\
Rh- & 11 & 9 & 1 & 0 & 21 \\
Rh-\% & 3.3 & 3.8 & 0.4 & 0 & 8.6 \\
Total & 120 & 103 & 19 & 8 & 250 \\
Total\% & 48.0 & 41.2 & 7.6 & 3.2 & 100 \\
\hline
\end{tabular}

Table 3: Specificity of the antibody detected in the study population.

\begin{tabular}{lcc}
\hline Antibodies detected & Number & Percentage (\%) \\
\hline Anti-C & 1 & 0.4 \\
Anti-E & 3 & 1.2 \\
Anti-Jsb & 1 & 0.4 \\
Anti-K & 2 & 0.8 \\
Mixed field & 3 & 1.2 \\
Unidentified & 1 & 0.8 \\
Negative & 238 & 95.2 \\
Total & 250 & 100.00 \\
\hline
\end{tabular}

antibody screening method was $41.6 \%$. The overall prevalence of irregular antibodies was $4.8 \%$.

\section{DISCUSSION}

Irregular RBC antibodies found in the sera of pregnant women have been studied in many parts of the world where pre-natal immunohaematologic care is given due priority. In this study, the frequency of irregular antibodies in maternal serum was $4.8 \%$. This appears high when compared with values from developed countries like Sweden (0.5\%), Netherlands (2.7\%), and lower when compared with values from developing countries where higher frequency values of 10.2\% in Mexico, and 20\% anti D were reported [3-6].

The most frequent and potentially significant nonanti-D antibody in our study was anti-E (1.2\%) followed by anti-K (0.8\%) then anti-C (0.4\%) and anti-Jsb (0.4\%). Bowel found an incidence of $14 \%$ in D+ pregnant women which was found to be most frequent in his study contrary to the results in this study where anti-E is most frequent [7]. Anti-E can be a naturally occurring IgM antibody, however IgG anti-E can be found in the sera of pregnant women with a history of previous transfusions and pregnancies. This immune form of anti-E is able to cause a mild to moderate HDN [8]. HDN caused by anti-C is usually mild as the $\mathrm{C}$ antigen has weak immunogenicity [7-11]. 
Table 4: Blind compatibility test results using the screened sera of patients (anti globulin cross match).

\begin{tabular}{lcc}
\hline Crossmatch results & Number & Percentage (\%) \\
\hline Compatible & 245 & 98.0 \\
Incompatible & 5 & 2.0 \\
\hline
\end{tabular}

Table 5: Clinical utility of antibody screening as a surrogate to antiglobulin cross match.

\begin{tabular}{lccc}
\hline $\begin{array}{l}\text { Antiglobulin } \\
\text { Crossmatch }\end{array}$ & Positive & Negative & Total \\
\hline Incompatible (+) & $\mathrm{TP}(5)$ & $\mathrm{FP}(0)$ & 5 \\
Compatible (-) & $\mathrm{FN} \mathrm{(7)}$ & $\mathrm{TN}(238)$ & 245 \\
Total & 12 & 238 & 250 \\
\hline
\end{tabular}

Positive AB screen includes identified, mixed field and unidentified reaction

$\mathrm{TP}=$ True positive, $\mathrm{FP}=$ False positive

$\mathrm{FN}=$ False Negative, $\mathrm{TN}=$ True negative

$\mathrm{PPV}=$ Positive predictive value,

$\mathrm{NPV}=$ Negative predictive value

Incompatible results $=$ positive results

Compatible results $=$ negative results

Sensitivity $=\mathrm{TP} / \mathrm{TP}+\mathrm{FN}=5 / 12 \times 100=41.6 \%$

Specificity $=\mathrm{TN} / \mathrm{TN}+\mathrm{FP}=238 / 238 \times 100=100 \%$

$\mathrm{PPV}=\mathrm{TP} / \mathrm{TP}+\mathrm{FP}=5 / 5 \times 100=100 \%$

$\mathrm{NPV}=\mathrm{TN} / \mathrm{FN}+\mathrm{TN}=238 / 245 \times 100=97.1 \%$

Efficiency $=\mathrm{TP}+\mathrm{TN} / \mathrm{TP}+\mathrm{FP}+\mathrm{FN}+\mathrm{TN} \times 100=238 / 245 \times 100=48.6 \%$

Prevalence $12 / 250 \times 100=4.8 \%$

Taking incompatible Crossmatch as $100 \%$

Number of incompatible crossmatch $=100 \%$

Number of incompatible crossmatch with an antibody detected 5/12 x $100 \%=41.6 \%$ Percentage safety $=41.6 \%$ (safety range $99-99.9 \%$ )

Anti-K was seen in this study with a frequency of $0.8 \%$. The frequency of $\mathrm{K}$ antigen in this locality is not yet known but it is known that after the $\mathrm{D}$ antigen, the $\mathrm{K}$ antigen is the most immunogenic. HDN caused by anti$\mathrm{K}$ can be severe [9]. There is evidence that anti-K can recognize $\mathrm{K}$ antigens expressed in the early stage of erythroid development in the fetal liver and can cause anemia by suppressing erythropoiesis [12-14]. Jsb has been reported to be common among people of African jessant. Anti-Jsb was the least frequent of all the four specific cities and has been known to be weakly immunogenic. Anti-D was not seen in this study in contrast to $20 \%$ anti-D found among pregnant women in Saudi Arabia [4]. Jeremiah and Buseri [15] reported Rhesus antigen and phenotype frequencies in Port Harcourt as follows. D neg (5.0\%), C neg (82.3\%), C neg (0.2\%), E negative $(79.5 \%)$ and e neg (1.3\%). It is therefore expected that anti-C and anti-E will occur more frequently in this locality while anti-D will be less common. This probably may explain why anti-D was not encountered in this investigation. Contrastingly, the frequency of D-negative has been reported to be approximately 15 percent among Caucasians and 20$30 \%$ in Middle East and some West African countries. It is not surprising that variable frequencies of unexpected antibodies were obtained in different region of the globe. However, a more detailed population study with larger sample size may need to be earned out using more sensitive methods to arrive at a more accurate figure.

Maternal serum is screened to make sure pregnant mother has no antibodies to react with fetal cells. Haemolytic disease of the foetus and newborn is caused by the mother's IgG antibodies crossing the placenta and attaching to the baby's red blood cells. It is therefore necessary to know as early as possible in the pregnancy whether HDN can be a possibility.

Determining the specificity of an unexpected alloantibody is important in prenatal testing. If the antibody specificity is known, it is possible to test donor blood for the presence of the corresponding antigen. In prenatal testing, knowledge of the specificity of the antibody helps predict the likelihood of the haemolytic disease of the newborn.

In most settings, antibody screening is done as part of pre-transfusion tests but the question as to its use as a surrogate to cross-matching procedure in emergency situation still remain not clear. In this study, a full blind crossmatch was performed in order to assess the safety level of antibody screening procedures as a surrogate to crossmatch. This study did not show the antibody screening procedure to reach the expected safety level of 99\%. The safety was low (41.6\%) but with a high specificity of $100 \%$, it can be used to select blood in advance for patients undergoing surgery in order to reduce the incidence of haemolytic transfusion reaction. Apart from having a low safety level of $41.6 \%$, it has earlier been reported that the "type and screen" porocedure has the weakness that antibodies to rare non-polymorphic antigens will not be detected (approximately $0.06 \%$ of cases), but the antibodies missed are rarely of clinical importance $[16,17]$.

Many of the red blood cell (RBC) alloantibodies of the Rhesus system have been associated with HDFN; however, the severity of the disease is usually the greatest with anti-D [18]. Prevention of RhD HDFN became feasible in the late 1960 s after pioneering research by Finn Clarks and Freda; there was a dramatic decline in Rh HDFN [19, 20]. Since then other Rh and non-Rh red cell alloantibodies have become relatively more important and are now responsible for the greater proportion of the HDFN cases. Anti-c and anti-E are the most common implicated non-D Rh antibodies in the pathogenesis of HDFN [21]. In this study, anti-E was found to be most frequently and this supports the earlier report to a large extent. Another study assessed the outcomes of anti-E in pregnancy and they concluded that a substantial proportion of infants are sufficiently affected by anti-E and suffer from clinically significant HDFN. In that study, $21 \%$ of the affected infants required exchange transfusion and $10 \%$ had severe or very severe disease and they concluded that anti-E titres and poor predictor of HDFN severity. Another study also showed that anti-E was a caused of moderately severe HDFN [7].

Most (95.2\%) of the pregnant women who participated in this study showed no antibodies i.e. they 
were non-immunized. Most of the immunized women $(\mathrm{n}=12,4.8 \%)$ developed alloantibodies of the non-D Rhesus and Kell blood groups.

The study shows that immunization due to antibodies belonging to the Rhesus system is $1.6 \%$ (i.e. non-D Rhesus antibodies) of all examined Port Harcourt pregnant women. Anti- D antibodies were not encountered in this study. It is possible the use of rhesus immunoglobulin anti-D to prevent sensitization due to anti-D could have led to the decrease in the incidence of anti-D antibodies. Besides the percentage of D-negative women in our locality is quite small when compared with E-negative and C-negative (15).

Anti-C was found in $0.4 \%$ of the immunized patients. Baker et al., [22] reported one case on a group $\mathrm{A} \mathrm{Rh}$ positive, $\mathrm{C}$ negative woman in whom anti-C was developed as a result of blood transfusion in childhood.

In summary, the number of antibodies against antigen of the rhesus system formed the highest percentage $(1.6 \%)$ of the alloantibodies detected. The Kell system antibodies were found only in $1.2 \%$ of the total antibodies detected (anti-K and anti-Jsb).

$$
* * * * * * * * *
$$

\section{Author Contributions}

Zaccheaus Awortu Jeremiah - Substantial contributions to conception and design, Acquisition of data, Analysis and interpretation of data, Drafting the article, Revising it critically for important intellectual content, Final approval of the version to be published

Augustina Mordi - Substantial contributions to conception and design, Acquisition of data, Analysis and interpretation of data, Drafting the article, Revising it critically for important intellectual content, Final approval of the version to be published

\section{Guarantor}

The corresponding author is the guarantor of submission.

\section{Conflict of Interest}

Authors declare no conflict of interest.

\section{Copyright}

(C) Zaccheaus Awortu Jeremiah et al. 2011; This article is distributed under the terms of Creative Commons attribution 3.0 License which permits unrestricted use, distribution and reproduction in any means provided the original authors and original publisher are properly credited. (Please see www.ijbti.com/copyrightpolicy.php for more information.)

\section{REFERENCES}

1. Poole J, Daniels G. Blood group antibodies and their significance in transfusion medicine. Transfus Med Rev 2007;21:58-71.
2. Eneh AU, Oruamabo. Neonatal Jaundice in a Sepcial Care Baby Unit (SCBU) in Port Harcourt, Nigeria: a prospective study. Port Harcourt Med J 2008;2:1107 .

3. Jovanovic - Srzentic S, Djokic M, Tijanic N, et al. Antibodies detected in samples from 21, 730 pregnant women. Immunohematology 2003;19:892.

4. Naje AA and Abbas HA, Red blood cell Alloimmunization among Saudi Pregnant women in the Central Province of Saudi Arabia. Kuwait MedJ 2008;40:116-23.

5. Koelewiyn JM, Vrijhotte, TGM, Vander-Schoot CE. Effect of screening for red cell antibodies other than anti-D to detect haemolytic disease of the fetus and newborn: A postulation study in Netherlands. Transfusion 2008;48:941.

6. Filbey D, Hanson U, Wesstrom G. The prevalence of red cell antibodies correlated to the outcome of the newborn. A 12 year study in central Sweden. Acta Obstet Gynecol Scand 1995;74:687-92.

7. Bowel PJ, Inskip MJ, Jones MN. The significance of anti-C alloimmunization in pregnancy. Clin Lab Haematol 1998;10:251-5.

8. Cheepsattayakorn R, Fongsatitkul L, Chotmaruemol $\mathrm{S}$, et al. Anti-E as a cause of hemolytic disease of the Nnewborn. J Med Assoc Thailand 1997;80(suppl.1):S1-4.

9. Mollison PL, Engelfriet CP, Contreras M. Blood transfusion in clinical medicine1oth ed Oxford: Blackwell Scientific Publications. 1997.

10. Daniels GL, Flegel WA, Fletcher A, et al. International Society of Blood Transfusion Committee on Terminology for Red Cell Surface antigens. Cape Town report. Vox Sanguinis 2007;92:250-3.

11. Zupanska B. Clinical significance of alloantibodies. In: Red cell immunohaematology. Proceedings of the European School of Transfusion Medicine 1998:59-66.

12. Hadley AG. A Comparison of in vitro tests for predicting the severity of haernolytic disease of the foetus and newborn. Vox Sang 1998;74(suppl 2):375-83.

13. Moise KJ Jr. Non-anti-D Antibodies in Red-cell alloiminimization. European J Obstet Gynecol Reprod Biol 2000;92(1):75-81.

14. Vaughan Jl, Manning M, Warwick RM, et al., Inhibition of erythroid progenitor Cells by anti-Kell Antibodies in Fetal alloimmune anemia. N Engl $\mathrm{J}$ Med 1998;338:798-3.

15. Jeremiah ZA, Buseri FI. Rh antigen and phenotype frequencies and probable genotypes for the four main ethnic groups in Port Harcourt Immunohematology 2003;19:86-8.

16. Oberman HA, Bames BA, Friedman BA. The risk of abbreviating the major crossmatch in $\mathrm{u}$ rgent or massive transfusion. Transfusion 1978;18:137-41.

17. Walker RH. Is a crossmatch using the indirect antiglobulin test necessary for patients with a negative antibody screen. In: Polesky HF, Walker RH (eds). Safety in Trasnfusion Practices. Skokie IL, College of American Pathologists 1982.

18. Wagner T, Resch B, Legler TJ. Severe HDN due to Anti-Ce that Required Exchange Transfusion. Transfusion 2000;40:571-4. 
19. Finn R, Clarke CA, Donohoe WT et al. Experimental Studies on the Prevention of RhHaemolyticDisease. Brit Med J 1961;1:1486-90.

20. Freda BJ, German JC, Pollack W. Successful prevention of experimental $\mathrm{Rh}$ sensitization in man with Ami Rh Gamma Globulin Antibody Preparation: A preliminary Report, Transfusion 1964;4:26-32.

21. Moran P, Robson SC, Reid MM. Anti-E in Pregnancy. BritJ Obstet Gynaecol 2000;107:1436-8.

22. Baker JW, Harrison KL, Harvey PJ. Anti-C hemolytic disease requiring intrauterine and exchange transfusion. Med JAustralia 1981;2:296. 